\title{
PROSPEK DAN TANTANGAN KELEMBAGAAN BADAN USAHA MILIK DESA DI DESA MEGU CILIK KECAMATAN WERU KABUPATEN CIREBON
}

\author{
Sam'un Jaja Raharja, Herwan Abdul Muhyi, Rivani, dan Zaenal Muttaqin \\ Departemen Ilmu Administrasi Bisnis, Fakultas Ilmu Sosial dan Ilmu Politik, Universitas Padjadjaran \\ E-mail : s.raharja2017@unpad.ac.id; harja_63@yahoo.com; herwan-am@yahoo.com \\ rivasip@yahoo.com ; zaesae.muttaqin@gmail.com
}

\begin{abstract}
ABSTRAK. Permasalahan utama adalah bagaimana Badan Usaha Milik Desa dapat segera terbentuk dan dapat dikelola serta berjalan secara efektif dan produktif? Tujuan Pelatihan Pengelolaan Badan Usaha Milik Desa di Desa Megu Cilik adalah membantu masyarakat menuju terbentuknya BUM Desa, tersusunya struktur organisasi dan Anggaran Dasar - Anggaran Rumah Tangga (AD - ART) BUM Desa, meningkatnya kompetensi kewirausahaan dan manajemen bisnis Pengelola BUM Desa dan hasil akhir adalah peningkatan perekonomian masyarakat desa. Metode yang diterapkan, pertama Diskusi Pembentukan BUM Desa, diskusi struktur organisasi, proses Penyusunan AD - ART. Kedua, Pelatihan Pengelolaan dan Workshop Kewirausahaan dan Manajemen Bisnis untuk peserta serta Calon Tim Pengurus/ Pengelola BUM Desa. Pelaksanaan kegiatan pengelolaan Badan Usaha Milik Desa dilakukan langkah-langkah (1) survei dan pemetaan kondisi eksisting (2) Penilaian kebutuhan (need assement) pelatihan. Khalayak sasaran sebanyak 26 (dua puluh enam orang) yang terlibat pada kegiatan yang diselenggarakan dengan unsur-unsur: Kepala Desa, Sekretaris Desa, Para Kepala Urusan, Para Ketua RW, Para Kepala Dusun dan calon Pengelola Badan Usaha Milik Desa Megu Cilik. Khalayak sasaran memperoleh tambahan pengetahuan, diantaranya hakekat dan tujuan Badan Usaha Milik Desa, bidang organisasi, tatacara menggali potensi dan penyusunan rencana bisnis. Untuk keberlanjutan program disarankan perlunya pendampingan lanjutan.
\end{abstract}

Kata kunci: prospek dan tantangan; BUM Desa; kewirausahaan; manajemen bisnis

ABSTRACT. The main problem is how can village-owned enterprises be established and can be managed and run effectively and productively? The objective of the Training in Management of BUM Desa in Megu Cilik Village is to help the community towards the formation of BUM -Desa, the disintegration of the organizational structure and Bylaws of the Village BUM Desa, increasing entrepreneurial competence and business management of BUM-Desa managers and the final results are improving the economy of rural communities. The method applied, the first discussion was the formation of BUM Desa, organizational structure discussion, the process of preparing the AD - ART. Second, Management Training and Entrepreneurship and Business Management Workshop for participants as well as Prospective BUM-Desa Management Team. The implementation of the management activities of Village-Owned Enterprises is carried out the steps (1) survey and mapping of existing conditions (2) Training needs assessment. The target audience of 26 (twentysix people) is involved in activities organized with elements of: Village Head, Village Secretary, Head of Affairs, Head of RW, Head of Hamlet and prospective Management of BUM Desa Megu Cilik. The target audience obtains additional knowledge, including the nature and objectives of Village-Owned Enterprises, the field of organization, procedures for exploring potential and preparing business plans. For the sustainability of the program it is suggested the need for further assistance.

Key words: prospects and challenges; BUM Desa; entrepreneurship; business management

\section{PENDAHULUAN}

Desa Megu Cilik merupakan salah satu desa di Kecamatan Weru Kabupaten Cirebon yang belum memiliki Badan Usaha Milik Desa (BUM Desa). Meski sudah adan himbauan dalam Undang-Undang Desa dan memiliki potensi usaha yang dapat dikembangkan. Disisi lain pada Kantor Desa Megu Cilik Kecamatan Weru Kabupaten Cirebon ini sudah terdapat potensi usaha yang akan dikembangkan melalui Badan Usaha Milik Desa (BUM Desa) yaitu pemanfaatan lahan untuk dijadikan kios. Sementara itu penduduk Desa Megu Cilik Kecamatan Weru Kabupaten Cirebon pada umumnya bermata pencaharian sebagai buruh industri serta pengrajin industri rumah tangga yang tersebar Kabupaten dan Kota Cirebon. Untuk mengurangi ketergantungan terhadap mata pencaharian tertentu saja dan sejalan dengan amanat peraturan perundangan mengenai Badan Usaha Milik Desa, pemerintah Desa Megu Cilik dan jajarannya sepakat untuk merintis dan membangun Badan Usaha Milik Desa sebagai upaya untuk meningkatkan pemberdayaan ekonomi masyarakat.
Secara normatif menurut Peraturan Menteri Desa dan Daerah Tertinggal dan Transmigrasi, yang dimaksud dengan BUM Desa, adalah badan usaha yang seluruh atau sebagian besar modalnya dimiliki oleh Desa melalui penyertaan secara langsung yang berasal dari kekayaan Desa yang dipisahkan. Badan Usaha Milik Desa merupakan pilar kegiatan ekonomi sebagai lembaga sosial (social institution) dan komersial (commercial institution), dengan ciri-ciri utama: (1) Badan usaha ini dimiliki oleh desa dan dikelola secara bersama; (2) Modal usaha bersumber dari desa (51\%) dan dari masyarakat (49\%) melalui penyertaan modal; (3) Operasionalisasinya menggunakan falsafah bisnis yang berakar dari budaya lokal; (4) Bidang usaha yang dijalankan didasarkan pada potensi dan hasil informasi pasar; (5) Keuntungan yang diperoleh ditujukan untuk meningkatkan kesejahteraan anggota (penyerta modal) dan masyarakat melalui kebijakandesa;(6)DifasilitasiolehPemerintah,Pemerintah Provinsi, Pemerintah Kabupaten dan Pemerintah Desa (7) Pelaksanaan operasionalisasi dikontrol secara bersama (Pemdes, BPD,dan anggota). 
Sedangkan jenis-jenis usaha yang dapat dijalankan meliputi; usaha jasa keuangan, jasa angkutan darat dan air, listrik desa, penyaluran sembilan bahan pokok, perdagangan hasil pertanian meliputi tanaman pangan, perkebunan, peternakan, perikanan, dan agrobisnis; industri dan kerajinan rakyat. Menurut klasifikasinya sebagai berikut (1) Serving (2) Banking (3) Renting: (4) Brokering (5) Trading (6) Holding (7) Contracting.

Sampai dengan saat ini pendirian BUM Desa belum dapat berjalan karena belum adanya kesepakatan di antara para pemangku kepentingan, kesiapan sumber daya manusia, Anggaran Dasar dan Anggaran Rumah Tangga belum final, serta calon pengelola masih membutuhkan pelatihan untuk menjalankan fungsinya dengan baik. Beberapa hal yang belum disepakati antara lain (1) bidang usaha yang akan dijalankan, terkait dengan dikhawatirkannya kemungkinan bidang usaha akan bertumpang tindih dan menjadi pesaing bidang usaha yang telah dijalankan secara perorangan (2) syarat-syarat calon manajer pengelola BUM Desa (3) besaran remunerasi bagi manajer pelaksana pengelola.

Berkaitan dengan analisis situasi, permasalahan dapat sebagai berikut: Bagaimana upaya pengembangan kelembagaan Badan Usaha Milik Desa di Desa Megu Cilik dapat berjalan secara efektif?

Tujuan yang ingin dicapai dari program ini yaitu (1) terlaksanakannya program penerapan ilmu pengetahuan kepada masyarakat terkait pengelolaan BUM Desa (2) Terwujudnya BUM Desa yang mampu menghasilkan laba serta memberikan manfaat ekonomi dan sosial bagi Pemerintah Desa dan masyarakat di Desa Megu Cilik.

Kegunaan yang diharapkan dari kegiatan ini adalah membantu masyarakat dalam (1) merealisasikan terbentuknya Badan Usaha Milik Desa (2) menyusun Anggaran Dasar - Anggaran Rumah Tangga BUM Desa (3) menyusun struktur, kelembagaan, dan Tim Pengelola BUM Desa (4) Meningkatkan kompetensi kewirausahaan dan manajemen bisnis Calon Pengelola BUM Desa (5) meningkatkan perekonomian masyarakat desa sehingga akan meningkatkan daya beli masyarakat dalam mewujudkan kesejahteraan.

\section{METODE}

Metode dalam uraian ini dijabarkan dalam dua uraian yang berbeda. Pertama metode pelaksanaan kegiatan pengabdian pada masyarakat. Metode yang digunakan dalam program pengabdian pada masyarakat ini ini dilaksanakan dengan metode sebagai berikut;

1. Pendampingan dalam proses penyusunan $A D-A R T$, Badan Hukum, serta pembentukan kelembagaan BUM Desa untuk para calon Tim Pengurus/Pengola BUM Desa.

2. Pelatihan dan Workshop Rencana Usaha Kewirausahaan dan Manajemen Bisnis untuk Calon Tim Pengurus/Pengelola BUM Desa.
Kedua metode penyusunan hasil pengabdian masyarakat dalam bentuk paper/artikel. Metode yang digunakan dalam penyusunan dan penulisan makalah paper ini menggunakan metode penelitian kualitatif. Data dikumpulkan melalui pengumpulan data primer berupa wawancara baik langsung maupun tertulis dengan naras umber yaitu Kepala Desa (Kuwu), Kasie Pembangunan Kecamatan dan para informan lainnya. Data sekunder diperoleh dari bahan-bahan berupa Profil Desa, peta desa dan sumber lainnya yang diperoleh melalui unduhan.

\section{HASIL DAN PEMBAHASAN}

Desa Megu Cilik merupakan desa hasil pemekaran yang sebelumnya Desa Megu. Desa ini dimekarkan pada tahun 1983. Luas wilayah Desa Megu Cilik 144,365 Ha, terdiri dari 3 Dusun, 3 FW dan 23 RT. Desa ini berbatasan dengan desa-desa di sekitarnya

- Sebelah Utara: Desa Setu Kulon Kecamatan Weru

- Sebelah Timur: Desa Megu Gede Kecamatan Weru

- Sebelah Selatan: Kelurahan Watu Belah Kecamatan Sumber

- Sebelah Barat: Desa Kertasari dan Tegal Wangi Kecamatan Sumber

Luas dan sebaran penggunaan lahan di Desa Megu Cilik pada umumnya digunakan untuk permukiman dan penggunaan lainnya

\begin{tabular}{|c|c|c|}
\hline No & Uraian & Luas (ha) \\
\hline 1 & Pemukiman & 99,380 \\
\hline 2 & Pesawahan & 36,00 \\
\hline 3 & Perkebunan & 0 \\
\hline 4 & Pekuburan & 3.426 \\
\hline 5 & Perkantoran & 0,59 \\
\hline 6 & Sarana Umum lain & 5,215 \\
\hline & Jumlah & 144,385 \\
\hline
\end{tabular}

Sumber: Profil Desa Megu Cilik, 2016

Jumlah penduduk Desa Megu Cilik sampai dengan tahun 2016 sebanyak 7.665 yang terdiri dari laki-laki 3.982 dan perempuan 3.783 dengan jumlah KK 4.122 KK. Data IPM Desa Megu Cilik sampai dengan saat ini belum tercatat dengan baik. Sedangkan bidang kesehatan memiliki tenaga kesehatan antara lain, 1 orang dokter umum, 1 orang bidan, 3 perawat, Posyandu 9, polindes 1, Desa Siaga 1 Kader PSM 26. Data prasarana Pendidikan sampai dengan tahun 2015 terdiri atas: 3 TK, 2 SD Negeri dan 1 SMP Swasta

Pada umumnya sarana mata pencaharian masyarakat Megu Cilik adalah usaha perdagangan, kerajinan las besi (konstruksi) dan makanan ringan. Di Desa Megu Cilikjuga terdapat sentra industri berupa pabrik kue di Blok Siwalan dan Lakar Jero. Sementara Las Besi di Blok Gembulu dan Makam Taman. Penduduk Desa juga banyak yang membuka usaha di luar Desa, seperti Tegalwangi dan lainlain 
Sektor jasa konstruksi dan perdagangan dan industri makanan ringan (kue) merupakan primadona perekonomian di Desa Megu Cilik serta menjadi sektor andalan. Sector tersebut menyerap tenaga kerja hamper $40 \%$ jumlah penduduk Megu Cilik, termasuk turunan dari industri kue berupa industri rumahan dan turunan industri konstruksi berupa industri las teralis, pagar dan lain-lain.

\section{Deskripsi Kondisi Eksisting BUM Desa Megu Cilik}

Secara umum berdasarkan survei awal ditemukan adanya beberapa masalah pengelolaan BUM Desa di Desa Megu Cilik, yaitu:

1. Pendirian dan pembentukan BUM Desa belum berjalan efektif karena belum adanya kesepakatan dan titik temu di antara para pemangku kepentingan yaitu (1) bidang usaha yang akan dijalankan, terkait dengan dikhawatirkannya kemungkinan bidang usaha akan bertumpang tindih dan menjadi pesaing bidang usaha yang telah dijalankan secara perorangan (2) syaratsyarat calon manajer pengelola BUM Desa (3) besaran remunerasi bagi manajer pelaksana pengelola

2. Calon Pengurus dan pengelola BUM Desa belum dapat mulai bekerja, karena belum ada kejelasan status kelembagaan usaha

3. Lahan usaha sudah siap untuk dibangun berupa lahan kosong

\section{Deskripsi Kegiatan Pengembangan Kelembagaan BUM Desa Megu Cilik}

Sesuai dengan permasalahan sebagaimana diidentifikasi pada bagian pendahuluan, materi kegiatan yang diberikan dalam kegiatan ini adalah sebagai berikut;

\section{a. Materi Anggaran Dasar dan Anggaran Rumah}

\section{Tangga}

Materi ini diberikan sesuai dengan template yang telah tersedia atau disediakan oleh kementerian Desa dan Transmigrasi

\section{b. Materi struktur organisasi internal}

Materi ini berkaitan dengan struktur organisais sebuah BUM Desa yang menggambarkan bidang pekerjaan apa saja yang harus tercakup di dalam organisasi dan bentuk hubungan kerjanya: garis komando, garis pelaporan, garis pertanggungjawaban

\section{c. Materi Uraian pekerjaan}

Materi ini merupakan tindak lanjut dari materi tentang struktur organisasi. Dengan uraian pekerjaan untuk setiap pengelola agar dapat memperjelas peran dari masing-masing orang. Dengan demikian, tugas, tanggungjawab, dan wewenang pemegang jabatan tidak terjadi duplikasi dan menempatkan orang-orang yang kompeten di bidangnya.

\section{d. Materi Rencana usaha (business plan) dan} kewirausahaan

Untuk meningkatkan dan mengembangkan usaha BUM Desa, diberikan materi rencana usaha dan kewirausahaan. Denggan materi ini para pengelola diberikan wawasan tentang peluang usaha yang dapat dirintis dan dikembangkan

\section{Pembentukan Kelembagaan Badan Usaha Milik Desa Megu Cilik}

Sebagaimana dikemukaka pada bagian awal, bahwa BUM Desa Megu Cilik sampai dengan saat ini belum terbentuk karena belum adanya kesepakatan di antara para pemangku kepentingan. Salah satu hal yang paling krusial dan menjadi perdebatan adalah kemungkinan tumpang tindih dan persaingan antara usaha yang telah dijalankan oleh warga secara individual dan dengan bidang usaha yang akan dibuka dan menjadi lahan bisnis BUM Desa. Secara teoritis sebagaimana dikemukakan oleh Eko (2013) sebagai situasi "kontradiksi BUM Desa dan ekonomi lokal eksisting”. Oleh karena itu Eko menyaratakan:

"membangkitkan dan memfasilitasi tumbuhnya gerakan ekonomi lokal secara emansipatoris jauh lebih penting ketimbang institusionalisasi BUM Desa secara serentak dari atas. Dalam hal ini pemerintah tidak boleh mengabaikan tetapi memberikan pengakuan atas usaha desa yang sudah ada dan berjalan selama ini, terlepas, tanpa harus bergabung atau digabungkan atau dihapuskan oleh karena adanya BUM Desa. Jadi usaha tersebut diakui bahkan didorong perkembangannya terlepas bentuk badan usahanya berbeda dengan BUM Desa."

Disinilah terjadinya kontradiksi, disatu pihak ada perintah Undang-Undang yang mendorong Desa membentuk BUM Desa. Disisi lain harus memberikan pengakuan terhadap usaha yang sudah berjalan. Yang menjadi kekhawatiran adalah terjadinya kompetisi atau pertentangan yang tidak perlu, sehingga keduanya tidak berjalan maksimum, bahkan saling mematikan. Hal inilah yang menyebabkan mengapa kelembagaan BUM Desa Megu Cilik belum terbentuk

\section{SIMPULAN}

Berdasarkan hasil pelaksanaan pengabdian pada masyarakat dan pembahasan tentang Badan Usaha Milik Desa di Desa Megu Cilik Kecamatan Weru Kabupaten Cirebon dan pelatihahn manajemen bisnis dapat disimpulkan sebagai berikut: Pelatihan yang diberikan dengan melalui PPM pada BUM Desa Megu Cilik telah terlaksana untuk materi-materi (1) Materi Anggaran Dasar dan Anggaran Rumah Tangga (2) Materi struktur organisasi internal (3) Materi Uraian pekerjaan (4) Materi Rencana usaha (business plan) dan kewirausahaan; Materi atau target pembentukan kelembagaan BUM Desa secara formal tidak tercapai karena belum adanya kesepakatan di antara para pemangku kepentingan. Dengan demikian sampai dengan saat ini belum terbentuk secara resmi karena belum adanya 


\section{DAFTAR PUSTAKA}

Anonymous, 2008. Micro Credit Strategy Formulation Mission for the National Community Empowerment Program: Program Nasional Pemberdayaan Masyarakat (PNPM) Jakarta Yayasan "MICRA"

-, 2015 Mengawal Kebijakan Desa: Pendirian dan Pengelolaan Badan Usaha Milik Desa. Buku 7.http://kawaldesaku.blogspot.com/2016/01/ pendirian-dan-pengelolaan-badan- usaha.html. Kementerian Desa, Daerah Tertinggal dan Transmigrasi

\section{Profil Desa Megu Cilik tahun 2016}

Eko, Sutoro dkk., 2013. Membangun BUM Desa yang Mandiri, Kokoh dan berkelanjutan. Policy Paper

PATTIRO (2016). Identifikasi praktek berdesa (utamanya praktek baik di desa/good practices) paska implementasi UU Desa, 2016.

http://pattiro.org/2016/09/praktik-baik-desa-dalamimplementasi-undang-undang- desa/
Raharja, Sam'un Jaja (2008) Strategi Pengembangan Kelembagaan Ekonomi Perdesaan Dalam Menunjang Program Nasional Pemberdayaan Masyarakat: Tinjauan Perspektif Organisasi. Jurnal Penelitian Universitas Mataram, Vol 2 No. 10, Pebruari 2008, hal 71-87

Samadi, Arrafiqur Rahman, Afrizal (2015) Peranan Badan Usaha Milik Desa

Dalam Peningkatan Ekonomi Masyarakat (Studi pada BUM Desa Desa Pekan Tebih Kecamatan Kepenuhan Hulu Kabupaten Rokan Hulu). http://e- journal.upp.ac.id/index.php/fekon/article/ view/378

Sofyan, Ahmad (2015) Langkah Persiapan Pendirian Badan Usaha Milik

Desa http:/documents.tips/documents/langkah-persiapanpendirian-badan-usaha- milik-desadocx.html

Yustika, Erani (2006) Ekonomi Kelembagaan, Bayu Media Publishing. 